\title{
EXTRATROPICAL STORM GENERATED SWELL INDUCED VULNERABILITY EFFECT ON A TROPICAL ISLAND
}

\author{
Onat Yaprak, University of Hawai'i at Manoa, yaprak@hawaii.edu \\ Francis Oceana, University of Hawai'i at Manoa, oceanaf@hawaii.edu
}

\begin{abstract}
The high-energy swells in the Northern Pacific are generally due to extratropical cyclones during the winter season. Conserving most of their energy while traveling long distances, strong swells increase the susceptibility of coastal zones of remote islands by increasing their vulnerability. Understanding the vulnerability caused by distant source generated swells allows adaptive attempts to be taken to protect natural, social, cultural and economic assets. The extratropical cyclone trends and its relation to swells requires a need to quantify its effect on island coastlines. The vulnerability is a complex phenomenon that demands multidisciplinary approaches, methods, and data sources to estimates of the impacts objectively. The main problem when it comes to defining vulnerability of small island communities is that even the unforeseen elements affect their susceptibility because they are more prone to the impacts of climatic forcing. Therefore, in this study, we extend an existing approach to quantify how extratropical storm generated swells affect the vulnerability of remotely located tropical islands.
\end{abstract}

Our case study is for the island of Oahu, Hawaii. Oahu is a densely populated tropical island that consists of various types of beaches and under a high wave energy environment. These swells originate from extratropical storms generated near the Kuril and Aleutian Islands ( $\mathrm{Li}$ et al., 2016).

We analyze the atmospheric conditions that are needed to create strong swells that would reach the remote island of Oahu, Hawaii, and hindcast the swells formed by these cyclone conditions in the Northern Hemisphere from 2008-2016. The strong cyclones are identified using minimum mean sea level pressure and geopotential height, and maximum vorticity from the hourly forecast dataset of NCEP Climate Forecast System six hourly Reanalysis. The sea state hindcast is obtained from the third-generation wave model WAVEWATCH III by using wind field data $10 \mathrm{~m}$ above the surface level. The characteristics of these swells during the high wave energy season are obtained on the grids surrounding the island in three hourly intervals. The average top $10 \%$ of wave height and period and the power that the swells generate in the area is used as input to calculate the swell exposure in a vulnerability model.

The vulnerability of the island of Oahu is defined by calculating a relative exposure of the $250 \mathrm{~m}$ shore segments by overlapping the coastal vulnerability index (CVI) variables of topography, bathymetry, surge exposure, sea level rise, the impact of natural habitats, coastal defense structures, population and climatic forcing. We use a GIS-based model developed by Natural Capital Project Integrated Valuation of Ecosystem Services and Tradeoffs tool (InVEST) ("InVEST Coastal Vulnerability Model," 2016) Version, 3.3.2. The CVI map visualize their overlaying spatial distribution, which gave a better understanding of the immediate action points for climatic forcing impacts. The ranking system based on the proposed methods of Gornitz, (1990) and Hammar-Klose and Thieler, (2001) is used to evaluate the overall coastal exposure of the area. The ranking system ranges from very low (1) to very high (5) and the exposure is the geometric average of the input layer ranks of that shoreline segment. The ranks are categorized by the relative percentile range of the input layers. Three vulnerability scenarios are generated: i) without climatic forcing, ii) only extratropical storms generated swell as climatic forcing and iii) wind wave state of the climatic forcing between 2008 and 2016. The effect of climatic forcing layer is demonstrated by applying ANOVA with Tukey-Kramer $p$ value test. The significant difference between the wave exposure variables between the scenarios and comparison with the overall exposure of the region quantifies the swell impacts in high wave energy environments during winter.

The coastal vulnerability map created according to scenario iii is shown in Figure 1 (Onat et al., 2018). Each point represents a shoreline segment. Arrows indicate the dominant swell directions (Vitousek \& Fletcher (2008)). The general exposure (CVI) is ranked from 1 (very low exposure) to 5 (very high exposure). As it can be seen from Figure 1, the vulnerability of the coasts facing the north pacific swells and southern swells is high, reaching up to a rank of 3.91 (high exposure) for the northern part of the island.

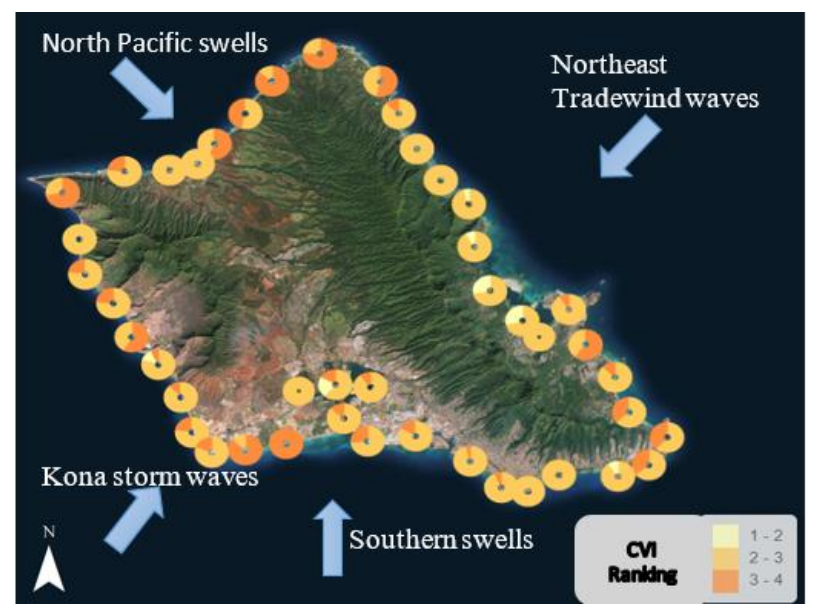

Figure 1 - Scenario iii coastal exposure of Oahu and dominant wave directions (Onat et al., 2018).

The three generated scenarios demonstrate how the swells coming from Northern Hemisphere affect the current vulnerability of the island. The study demonstrates the current vulnerability of the island of Oahu and the amount of vulnerability created by these swells and its interaction with the biophysical and socioeconomic well-being of the Island. We find that the extratropical swells have more of an impact on the general exposure of the island except for the south shore, which makes swells a significant contributing factor to vulnerability. 
We devise a strategy which allows us to define vulnerability in small and densely populated island communities affected by high wave energy environments. The coastal vulnerability index maps that are produced can be used by the decision makers to take action to increase the resilience of critically exposed shoreline segments.

\section{REFERENCES}

Gornitz V. (1990). Vulnerability of the east coast, U.S.A. to future sea level rise. JCR, vol. 9 pp. 201-237.

Hammar-Klose E.S., Thieler, E.R. (2001). Coastal Vulnerability to Sea-Level Rise: A Preliminary Database for the U.S. Atlantic, Pacific, and Gulf of Mexico Coasts. U.S. Geological Survey, No. 68.

InVEST ver. 3.3.2 Natural Capital Project, 2016.

Sample Datasets [WWW Document]. URL

http://data.naturalcapitalproject.org/invest-data/3.3.2/ (accessed 10.6.17).

Li, N., Cheung, K.F., Stopa, J.E., Hsiao, F., Chen, Y.-L., Vega, L., Cross, P., 2016. Thirty-four years of Hawaii wave hindcast from downscaling of climate forecast system reanalysis. Ocean Model. 100, 78-95. doi:10.1016/j.ocemod.2016.02.001

Onat, Y., Francis, O.P., Kim, K., 2018. Vulnerability assessment and adaptation to sea level rise in high-wave environments: A case study on O'ahu, Hawai'i. Ocean Coast. Manag. 157, 147-159. doi:10.1016/j.ocecoaman.2018.02.021

Vitousek Sean, Fletcher Charles (2008): Maximum annually recurring wave heights in Hawai'l, Pacific Science vol. 62.4 pp. 541-553. 